\title{
Determining the Best Sectioning Method and Intestinal Segment for Morphometric Analysis in Broilers
}

http://dx.doi.org/10.1590/1516-635x1702145-150

\section{mAuthor(s)}

Gava MS

Moraes LB"

Carvalho D"I

Chitolina GZ"I

Fallavena LCB ${ }^{\mathrm{IV}}$

Moraes HLS"I

Herpich J"I

salle CTPIII

Universidade do Sul de Santa Catarina (UNISUL)

" Instituto de Pesquisas Veterinárias Desidério Finamor (IPVDF) - Fundação Estadual de Pesquisa Agropecuária (FEPAGRO)

III Centro de Diagnóstico e Pesquisa em Patologia Aviária (CDPA) - Universidade Federal do Rio Grande do Sul (UFRGS).

iv Universidade Luterana do Brasil (ULBRA).

\section{Mail Address}

Corresponding author e-mail address Lucas Brunelli de Moraes

Rua Correa Lima, 970, Santa Tereza, Porto Alegre, RS, Brasi

E-mail: lucasbmoraes@gmail.com

\section{nKeywords}

Image, intestine, morphometry, poultry, villus.

\section{ABSTRACT}

Brazilian poultry production is very efficient and demands maximum broiler performance. Therefore, digestive system pathologies have a relevant role. Considering it is difficult to obtain consistent information on intestinal morphometric analysis, this study aimed at establishing essential and clear criteria for the collection of intestinal segments for morphometric analysis. Fifteen 13-d-old broilers were sacrificed and three intestinal segments were collected per bird. Two 3-cm long sections were obtained from each of the intestinal segments. Samples were collected open or closed. The closed samples were transversely, hemicylindrically, or longitudinally sectioned. Samples were processed and stained with hematoxylin and eosin. The number of microscopic fields in each section was counted. Villi presenting the base clearly embedded in the submucosa, no damage or folds, and simple columnar epithelium at the tip were considered adequate for measurements. These villi were counted in each sample. The results shows that hemicylindrical sections presented the highest number of observation fields, with an average of 9.76 fields. Jejunum samples were among the three highest average villi counts, with 18.23 in longitudinal sections and 15.61 in hemicylindrical sections. The results of the present study indicate that hemicylindrical sectioning and jejunal samples were, respectively, the best sectioning method and the best intestinal segment for the morphometric analysis of the intestines of broilers.

\section{INTRODUCTION}

The poultry industry demands maximum performance from broilers. Consequently, digestive system pathologies are extremely relevant, as they may negatively affect broilers' economic potential and, according to Ferreira et al. (2012), increase processing losses due to lack of flock uniformity.

The intestinal mucosa consists of a layer of simple columnar epithelium (Kalil et al., 2000; Luna, 1968) and by villi. These projections of the lamina propria into the intestinal lumen increase nutrient digestion and absorption surface area. Despite the many studies in literature on intestinal morphometry, most do not clearly describe the methodology applied. Relevant data, such as the evaluated intestinal segment, the time between death and sample fixation, how the segments are sectioned, and criteria to measure the microstructures, are not informed (Alvarenga et al., 2004; Fukayama et al.; 2005, Okamoto et al., 2009 and Shiraishi et al., 2009). On the other hand, Caruso \& Demonte (2005), studying the histomorphometry of the small intestine of rats, describe the details of the methodology applied and of the measurement criteria used. The authors describe the time between 

Chitolina GZ, Fallavena LCB,

Moraes HLS, Herpich J, Salle CTP
Gava MS, Moraes LB, Carvalho D,

sample collection and fixation, staining technique, the method applied to measure villi and crypt depth, and number of villi evaluated per individual.

Considering the lack of agreement among the different authors that evaluated methods of intestinal sample collection and measured structures, the objective of the present study was to establish essential and clear criteria for broiler intestinal morphometric analysis. Firstly, the best method to collect and section intestinal samples was determined, and then the most adequate combinations of intestinal segmentsectioning method were evaluated.

\section{MATERIAL AND METHODS}

\section{Birds}

Fifteen 13-day-old Cobb broilers were housed in cages and offered feed and water ad libitum. Birds were sacrificed by neck dislocation, and the intestinal samples were collected immediately after death was confirmed.

\section{Determining the Best Sectioning Method and Intestinal Segment for Morphometric Analysis in Broilers}

\section{Sample collection}

In order to obtain samples of adequate size, $3-\mathrm{cm}$ long sections were collected from each intestinal segment (duodenum, jejunum, and ileum). Immediately after samples were cut, the intestinal lumen was washed with $10 \%$ buffered formalin in order to remove the lumen content. All samples were placed in individually identified flasks containing $10 \%$ buffered formalin.

Each intestinal segment was collected either closed (no exposure of the intestinal mucosa) or opened, with the mucosa exposed by longitudinal incision of the organ from the mesenteric border and then stapled on a paper card measuring $2 \times 3 \mathrm{~cm}$. Samples were stretched and stapled through the mucosa with the serosa placed in contact with the paper card.

Duodenum samples were obtained from two sections: close to the ventriculus (descending part) and close to the jejunum (ascending part). Proximal and distal fragments of the jejunum were collected, considering Meckel's diverticulum as the limit between these two fragments. Ileum samples were collected from the segment located between the ceca.

Table 1 - Sample collection and sectioning methods applied.

\begin{tabular}{l|l}
\hline Collection method & Sectioning method \\
\hline \multirow{3}{*}{ Close samples } & Transversal (T) - Figure 1 \\
\cline { 2 - 2 } & Longitudinal (L) - Figure 2 \\
\cline { 2 - 2 } & Hemicylindrical (H) - Figure 4 \\
\hline Open samples & Open stapled (OS) - Figure 4 \\
\hline
\end{tabular}

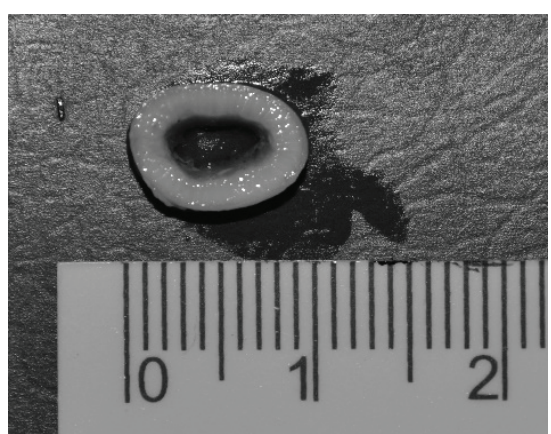

Figure 1 - Transversal section of the jejunum collected closed

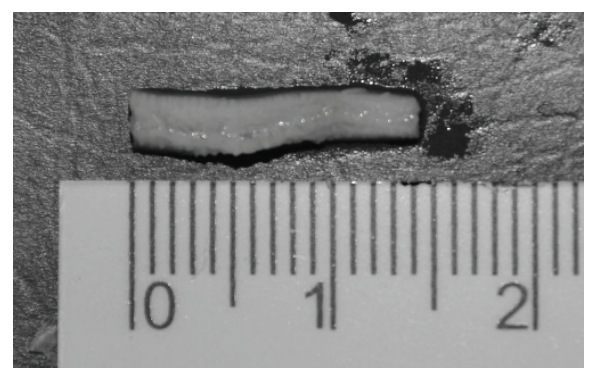

Figure 3 - longitudinal section of the jejunum collected closed

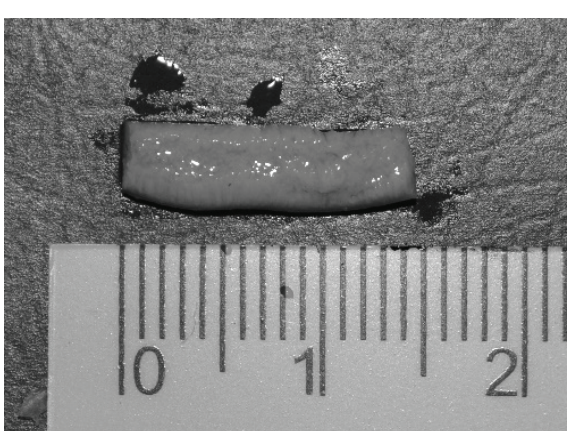

Figure $\mathbf{2}$ - Section of the jejunum collected open and stapled

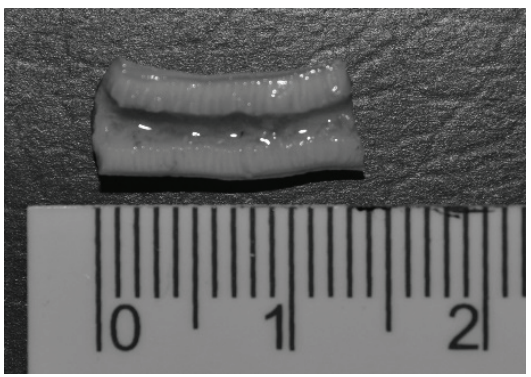

Figure 4-Hemicylindrical section of the jejunum collected closed 
Gava MS, Moraes LB, Carvalho D, Chitolina GZ, Fallavena LCB, Moraes HLS, Herpich J, Salle CTP

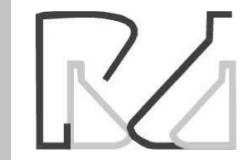

\section{Sectioning of the samples}

The intestinal samples were sectioned using four different methods. All samples were approximately $1-\mathrm{mm}$ thick. The longitudinal sections (hemicylindrical and longitudinal) were $15-\mathrm{mm}$ long. The sections as described in Table 1.

\section{Sample processing for histology}

Samples were dehydrated in graded concentrations of alcohol, cleared in xylene, and embedded in paraffin. Samples were then cut into $4-\mu \mathrm{m}$ thick sections and stained with hematoxylin-eosin.

\section{Observation field count}

Microscopic observation fields were counted under optical microscope (10x magnification) for each type of sample (Figure 5) of each intestinal segment, and the total number of observation fields was duly recorded.

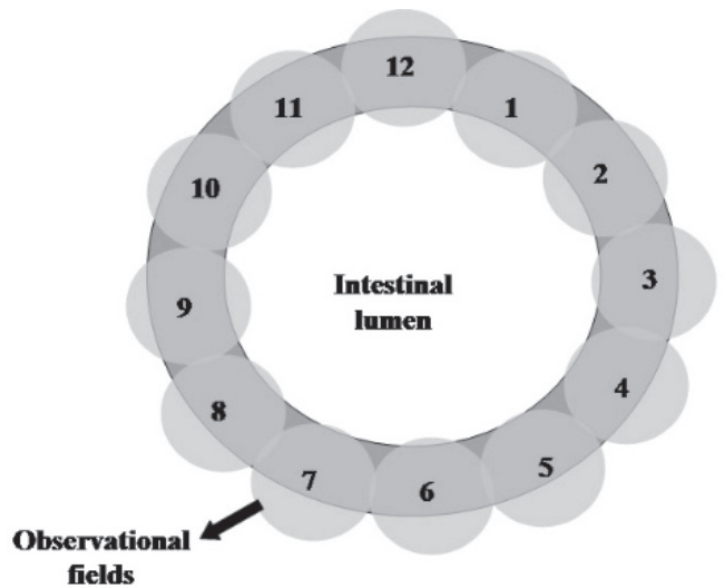

Transversal section

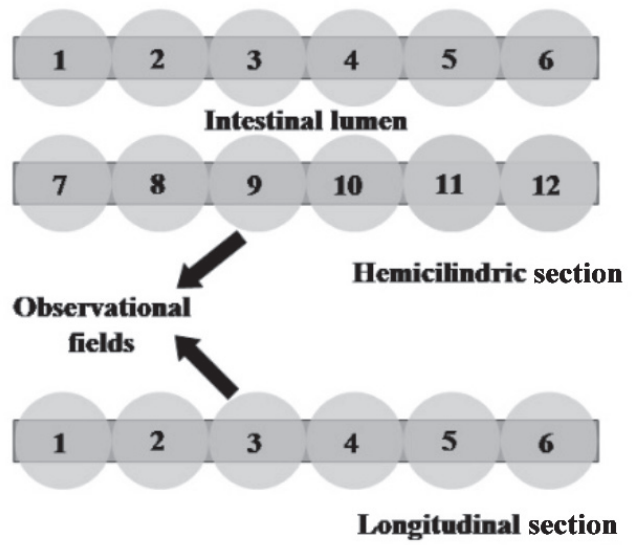

Figure $\mathbf{5}$ - Diagram of the section surface and of the observation fields of the different types of samples.
Determining the Best Sectioning Method and Intestinal Segment for Morphometric Analysis in Broilers

\section{Villus count}

Only the villi considered adequate for measurements were counted. A villus was considered adequate when its base was clearly embedded in the submucosa (10x magnification; Figure 6); its body did not present any discontinuity or folds (4x magnification; Figure 7); and simple columnar epithelium was present at the tip (40x magnification; Figure 8).

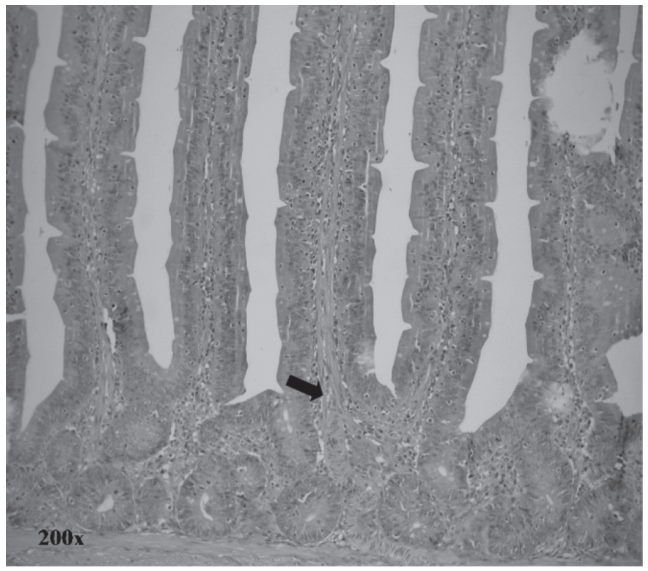

Figure 6 - Base of a villus considered adequate for measurement (arrow).

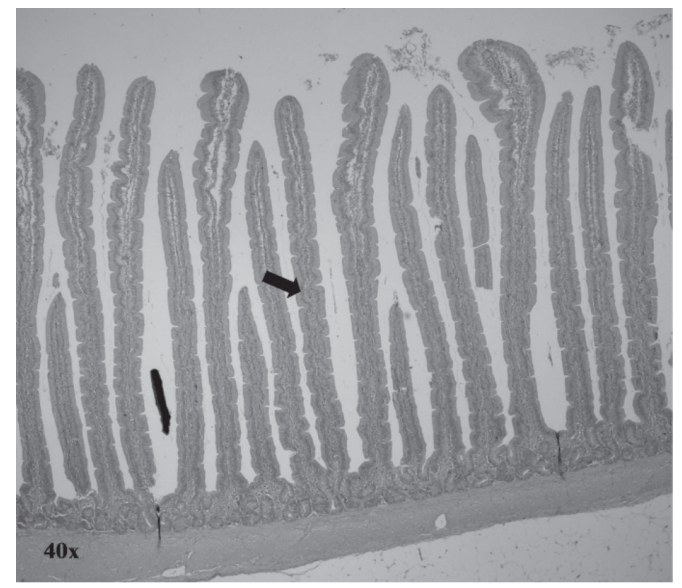

Figure 7 - Body of a villus considered adequate for measurement (arrow).

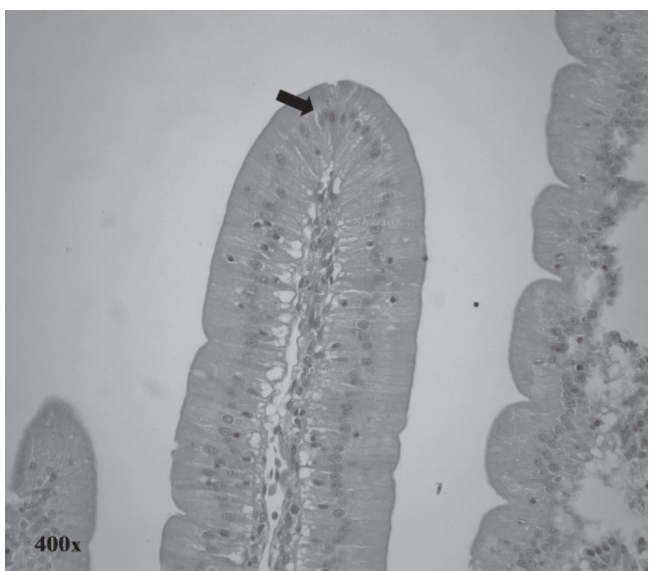

Figure $\mathbf{8}$ - Tip of a villus considered adequate for measurement, presenting simple columnar epithelium (arrow). 
Gava MS, Moraes LB, Carvalho D, Chitolina GZ, Fallavena LCB

Moraes HLS, Herpich J, Salle CTP

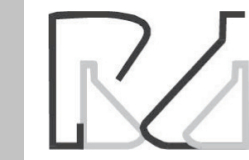

\section{Statistical analysis}

The collected data were submitted to one-way analysis of variance and means were compared by the test of Tukey-Kramer.

\section{RESULTS}

The results of observation field counts and number of villi considered adequate for measurement according to sample type and intestinal segment are shown in Tables 2 and 3.

Table $\mathbf{2}$ - Average number of observation fields according to sample type and intestinal segment.

\begin{tabular}{lll}
\hline Sample type & Number of samples & $\begin{array}{c}\text { Number of observation } \\
\text { fields }\end{array}$ \\
\hline HCPJ & 13 & $9.76^{\mathrm{a}}$ \\
\hline HCAD & 12 & $9.33^{\mathrm{ab}}$ \\
\hline HCPI & 14 & $9.21^{\mathrm{ab}}$ \\
\hline TCAD & 14 & $6.71^{\mathrm{abc}}$ \\
\hline LCAD & 14 & $6.28^{\mathrm{abc}}$ \\
\hline TCPJ & 10 & $6.20^{\mathrm{abc}}$ \\
\hline SODI & 13 & $6.15^{\mathrm{abc}}$ \\
\hline TCPI & 10 & $6.00^{\mathrm{abc}}$ \\
\hline LCPJ & 13 & $6.00^{\mathrm{bc}}$ \\
\hline SODJ & 13 & $5.69^{\mathrm{bc}}$ \\
\hline SODD & 13 & $5.30^{c}$ \\
\hline LCPI & 9 & $3.66^{\mathrm{c}}$ \\
\hline
\end{tabular}

Means followed by different superscripts are significantly different atp $\leq 0.05$

$\begin{array}{ll}\text { LCAD } & \text { Longitudinal closed ascendant duodenum } \\ \text { HCAD } & \text { Hemicylindrical closed ascendant duodenum } \\ \text { TCAD } & \text { Transversal closed ascendant duodenum } \\ \text { SODD } & \text { Stapled opened descendant duodenum } \\ \text { SODJ } & \text { Stapled opened distal jejunum } \\ \text { LCPJ } & \text { Longitudinal closed proximal jejunum } \\ \text { HCPJ } & \text { Hemicylindrical closed proximal jejunum } \\ \text { TCPJ } & \text { Transversal closed proximal jejunum } \\ \text { SODI } & \text { Stapled open distal ileum } \\ \text { LCPI } & \text { Longitudinal closed proximal ileum } \\ \text { HCPI } & \text { Hemicylindrical closed proximal ileum } \\ \text { TCPI } & \text { Transversal closed proximal ileum }\end{array}$

The results presented in Table 2 show that, independently of the intestinal segment (duodenum, jejunum, or ileum), the collection of "closed" samples and the "hemicylindrical" section provided the highest numbers of observation fields per sample.

Table 3 shows that jejunum samples provided higher average counts of villi adequate for measurement, and
Determining the Best Sectioning Method and Intestinal Segment for Morphometric Analysis in Broilers

that samples submitted to "hemicylindrical" section presented two out of the three highest average counts of villi adequate for measurement.

Table 3 - Average number of villi considered adequate for measurement in intestinal samples of 13-d-old broilers.

\begin{tabular}{lcc}
\hline Sample type & $\begin{array}{c}\text { Number of } \\
\text { samples }\end{array}$ & $\begin{array}{c}\text { n. of villi adequate for } \\
\text { measurement }\end{array}$ \\
\hline HCPI & 14 & $20.57^{\mathrm{a}}$ \\
\hline LCPJ & 13 & $18.23^{\mathrm{ab}}$ \\
\hline HCPJ & 13 & $15.61^{\mathrm{abc}}$ \\
\hline TCPJ & 10 & $5.90^{\mathrm{abc}}$ \\
\hline HCAD & 12 & $5.75^{\mathrm{abc}}$ \\
\hline SODD & 13 & $5.69^{\mathrm{abc}}$ \\
\hline TCPI & 10 & $2.90^{\mathrm{bc}}$ \\
\hline SODJ & 13 & $2.30^{c}$ \\
\hline LCPI & 9 & $1.88^{c}$ \\
\hline LCAD & 14 & $1.85^{c}$ \\
\hline SODI & 13 & $1.30^{c}$ \\
\hline TCAD & 14 & $0.64^{c}$
\end{tabular}

Means followed by different superscripts are significantly different at $p \leq 0.05$.

$\begin{array}{ll}\text { LCAD } & \text { Longitudinal closed ascendant duodenum } \\ \text { HCAD } & \text { Hemicylindrical closed ascendant duodenum } \\ \text { TCAD } & \text { Transversal closed ascendant duodenum } \\ \text { SODD } & \text { Stapled opened descendant duodenum } \\ \text { SODJ } & \text { Stapled opened distal jejunum } \\ \text { LCPJ } & \text { Longitudinal closed proximal jejunum } \\ \text { HCPJ } & \text { Hemicylindrical closed proximal jejunum } \\ \text { TCPJ } & \text { Transversal closed proximal jejunum } \\ \text { SODI } & \text { Stapled open distal ileum } \\ \text { LCPI } & \text { Longitudinal closed proximal ileum } \\ \text { HCPI } & \text { Hemicylindrical closed proximal ileum } \\ \text { TCPI } & \text { Transversal closed proximal ileum }\end{array}$

\section{DISCUSSION}

Literature reports a wide variety of methods for the collection of intestinal samples for histology. For instance, Alvarenga et al. (2004) collected 5-cm rings from each small intestine segment, whereas Okamoto et al. (2009) collected 1-cm long samples of the proximal duodenum that were opened by the mesenteric border. Shiriashi et al. (2009) collected ring-shaped samples of the ileum and washed them with a $0.9 \% \mathrm{NaCl}$ solution. Fukayama et al. (2005) collected $1.5-\mathrm{cm}$ long intestinal samples, which were immediately washed with distilled water and fixed in Bouin solution for 24 hours. Caruso \& Demonte (2005) collected $1-\mathrm{cm}$ samples of the small intestine of rats, fixed them in $10 \%$ formalin, refrigerated the samples 
Gava MS, Moraes LB, Carvalho D, Chitolina GZ, Fallavena LCB,

Moraes HLS, Herpich J, Salle CTP

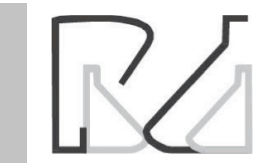

Determining the Best Sectioning Method and Intestinal Segment for Morphometric Analysis in Broilers for 24 hours, and then transferred them to a medium containing $70 \%$ alcohol.

This brief literature review illustrates the diversity of methods applied in histological studies of the intestine. Perhaps the only consistent feature among them is the lack of details on the methods used for sample collection. This was the motivation of the present study, as it was not possible to reproduce the methodology described by those authors. We decided to apply part of the mentioned methodologies and to evaluate some essential aspects, such as the number of observation fields and the number of villi considered adequate for measurement, as well as to clearly define which villus characteristics that are required to determine if the villi are adequate or not. These characteristics were not described in any of the researched studies. Some intestinal samples were collected and the segments opened by the mesenteric border, as described by Okamoto et al. (2009), while other samples were collected without opening, as suggested by Shiriashi et al. (2009). All sections were $1.5 \mathrm{~cm}$ long and were washed with a fixing solution, according to Fukuyama et al. (2005).

The small intestine samples that were collected and not opened and submitted to hemicylindrical section presented the highest number of observation fields, independently of intestinal segment. This result is in agreement with Kalil et al.(2000), who recommend that small intestine samples should always be sectioned in the longitudinal direction in order to obtain histological section which villi are not unduly increased.

The intestine is a very sensitive organ and needs to be handled with care. In the present study, strict criteria were adopted to consider that a villus was adequate for measurement. The villus body should not present any artifacts (folds, breaks, grooves, etc.), its base should be clearly embedded in the submucosa, and its tip should present simple columnar epithelium. Artifacts in the villus body may "reduce" its size, such as in the case of folds, or increase it, such as in the case of grooves or breaks. A villus base clearly embedded in the submucosa indicates that the villus belongs to the evaluated section, whereas the tip with simple columnar epithelium suggests that it was sectioned close to its sagittal line. The consideration of these characteristics provide higher measurement accuracy, as they prevent possible distortions. When these characteristics were taken into account when evaluating the villi, the samples obtained by hemicylindrical section were shown to be the most adequate for morphological evaluation, because they presented the highest number of microscopic observation fields and the highest number of villi considered adequate for measurement. In addition, because the jejunum presented the highest number of measurable villi and observation field counts, it is suggested that this intestinal segment is the most indicated for morphometric analyses.

\section{CONCLUSIONS}

Based on the results obtained in the present study, it was concluded that the samples that were collected closed and submitted to hemicylindrical section presented the highest number of observation fields, independently of intestinal segment. The jejunum is the most indicated intestinal segment for intestinal histomorphometric analysis, because it presented the highest number of villi considered adequate for measurement and due to its importance for nutrient absorption. In addition, it was observed that the structure of the intestines is very frail, requiring extreme care when handled. The present study may be used as the basis of future studies using intestinal morphometric analyses as it elucidated basic issues relative to sample collection method and processing.

\section{REFERENCES}

Alvarenga BO, Belletti ME, Fernandes EA, Silva MM, Campos LFB, Ramos SP. Efeitos de fontes alternativas de fósforo nas rações de engorda e abate sobre a morfologia intestinal de frangos de corte. Bioscience Journal 2004;20(3):55-59.

Caruso M, Demonte A. Histomorfometria do intestino delgado de ratos submetidos a diferentes fontes protéicas. Alimentos e Nutrição 2005;16(2):131-133.

Ferreira TZ, Sesterhenn R, Kindlein L. Perdas econômicas das principais causas de condenações de carcaças de frangos de corte em Matadouros-Frigoríficos sob Inspeção Federal no Rio Grande do Sul, Brasil. Acta Scientiae Veterinariae 2012:40(1):1021.

Fukayama EH, Bertechini AG, Geraldo A, Kato RK, Murgas LDS. Extrato de orégano como aditivo em rações para frango de corte. Revista Brasileira de Zootecnia 2005;34(6):2316-2326.

Kalil M, Zaltman C, Takiya CM. Arquitetura da mucosa intestinal. In: Souza HSP, Elia CCS. Imunologia da mucosa intestinal. São Paulo: Atheneu; 2000. p.11-39.

Luna GL. Manual of histologic - Staining methods of the armed forces institute of pathology. $3^{\mathrm{a}} \mathrm{ed}$. London: McGraw-Hill Book Company 1968.

Okamoto AS, Filho RLA, Lima ET, Moujaim JC. Histopatologia da mucosa intestinal de pintos tratados com Lactobaccillusspp. e desafiadas com Salmonella entérica, Subespécie entérica, Sorotipo Enteritidis. Ciência Animal Brasileira 2009;10(2):568-573.

Shiraishi CS, Azevedo JF, Silva AV, Santana DMG, Araujo EJA. Análise morfométrica da parede intestinal e dinâmica de mucinas secretadas no ileo de frangos infectados por Toxoplasma gondii. Ciência Rural 2009;39(7):2146-2153. 
